\title{
Pink tea challenge
}

\author{
Lucia D'Ulivo ${ }^{1}$
}

(C) Her Majesty the Queen in Right of Canada as represented by: NRC Canada 2017

We would like to invite you to participate in the Analytical Challenge, a series of puzzles to entertain and challenge our readers. This special feature of "Analytical and Bioanalytical Chemistry” has established itself as a truly unique quiz series, with a new scientific puzzle published every three months. Readers can access the complete collection of published problems with their solutions on the ABC homepage at http://www.springer.com/abc. Test your knowledge and tease your wits in diverse areas of analytical and bioanalytical chemistry by viewing this collection.

In the present challenge, pink tea is the topic. And please note that there is a prize to be won (a Springer book of your choice up to a value of $€ 100)$. Please read on...

\section{Meet the challenge}

Pink tea, also known as Noon chai, is a traditional Kashmiri beverage served with local pastries and dried fruit. Although typical from Kashmir, this tea is also found in Pakistan, where it is served on special occasions such as weddings or feasts, and during the winter time. Not to be confused with the sweet and spicy milk tea Masala chai, Noon chai does not require sugar, and has in fact a distinctive salty taste (indeed, the word noon means salty in Kashmiri language) [1].

It is quite hard to find a standard recipe for the Pink tea as it varies from family to family and from town to town.

Lucia D'Ulivo

Lucia.D’Ulivo@nrc-cnrc.gc.ca; lucia.dulivo@gmail.com

1 National Research Council of Canada, 1200 Montreal Road, ON, K1A 0R6 Ottawa, Canada
Traditionally, however, the Pink tea requires special tea leaves (e.g., Kashmiri chai), water, salt, baking soda, and milk. The tea leaves are soaked in a pot with water, which is then brought to boil. The tea is allowed boiling for a while, even an hour; salt and baking soda are then added under constant stirring. Afterwards, the flame is turned down and milk is added. At this point, the beverage assumes a vintage pink color (see Fig. 1).

\section{The challenge}

Besides Kashmiri chai (a blend of Darjeeling tea, green cinnamon, ground almonds, star anise, and cardamom), green tea leaves can also be used for the preparation of Noon chai. However, the use of white tea will not result in the pink beverage.

What are the chemical reasons for the pink color and why can we observe this phenomenon only with certain types of tea leaves?

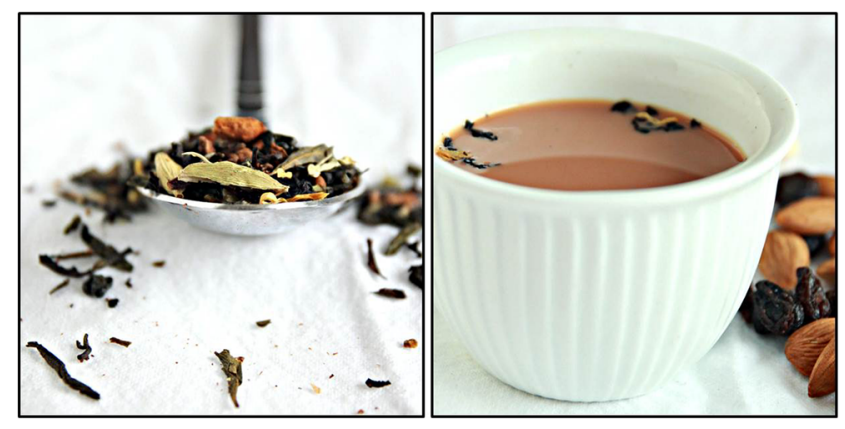

Fig. 1 Kashmiri chai blend (left) and the pink-colored tea prepared from it (right) 
Suppose that pink is no longer of interest and you want to obtain a green colored tea extract using the same procedure (boil tea leaves in water, add salt, baking soda, and milk).

What type of tea-such as black, green, or white tea, herbal or fruit tea-you would select to obtain "green" tea?

\section{References}

1. Balfour E. Cyclopaedia of India and of Eastern and Southern Asia, commercial, industrial and scientific: products of the mineral, vegetable and animal kingdoms, useful arts and manufactures. In: Scottish and Adelphi P, 2 ed; 1873. vol. V.
We invite our readers to participate in the Analytical Challenge by solving the puzzle above. Please send the correct solution to abc-challenge@ springer.com by September 1, 2017. Make sure you enter "Pink tea challenge" in the subject line of your e-mail. The winner will be notified by e-mail and his/her name will be published on the "Analytical and Bioanalytical Chemistry" homepage at http://www. springer.com/abc, and in the journal (volume 410/issue 01) where readers will find the solution and a short explanation.

The next Analytical Challenge will be published in 409/25, October 2017. If you have enjoyed solving this Analytical Challenge you are invited to try the previous puzzles on the ABC homepage. 